\title{
Immunopathological changes in the airways of stable lung transplant recipients
}

Gregory I Snell, Christopher Ward, John W Wilson, Bernadette Orsida, Trevor J Williams, E Haydn Walters transplantation, either in stable transplant patients or in those with chronic rejection (synonymous with bronchiolitis obliterans syndrome). ${ }^{1}$ The gross pathology of transplanted airways is recognised in the Lung Rejection Study Group's working formulation of lung rejection. ${ }^{12}$ Four separate entities are described: lymphocytic bronchitis and bronchiolitis, obliterative bronchiolitis, ${ }^{23}$ bronchomalacia, ${ }^{4}$ and bronchiectasis. ${ }^{3}$ There is an important distinction between histological obliterative bronchiolitis and the clinically defined bronchiolitis obliterans syndrome which does not require histological evidence of obliterative bronchiolitis.

Attention has focused on the assessment of acute "lung" rejection using transbronchial biopsy (TBB) specimens of lung parenchyma to categorise perivascular phenomena. The yield of useful bronchial tissue from such specimens is variable but frequently poor. Estimates for the sensitivity of diagnosing obliterative bronchiolitis from TBB specimens range from $15.2 \%{ }^{5}$ to $87 \%$. $^{6}$ Chamberlain and coworkers recently described a sensitivity of $17.1 \%$ and a specificity of $94.5 \%$ for histological obliterative bronchiolitis from one transbronchial lung biopsy procedure. ${ }^{7}$ It is probable that important early indicators of airway injury are being under-recognised and therapeutic opportunities missed, particularly with reference to the bronchiolitis obliterans syndrome. With current protocols the bronchiolitis obliterans syndrome remains the commonest cause of morbidity and mortality in survivors of lung transplantation beyond three months. The risk is estimated to be between $10 \%$ and $54 \%^{23}$ with an overall mortality rate of $50 \%{ }^{4}$

It is hypothesised that the pathogenesis of histological obliterative bronchiolitis involves lymphocyte mediated airway epithelial damage associated with increased expression of class II MHC antigens and an infiltrate of antigen presenting dendritic cells. ${ }^{8}$ The resulting stimulation of alloreactive CD4 lymphocytes is thought to lead to local cytokine release. ${ }^{9}$ Current concepts of fibrosis suggest that recruited macrophages and mast cells release tumour necrosis factor (TNF)- $\alpha$, interleukin (IL) -1 , and platelet derived growth factor (PDGF)- $\beta$ leading to fibroblast proliferation and subsequent collagen production. ${ }^{10}$ The actual pathway in human transplanted lung has yet to be defined but includes small and large airways, initially in an irregular distribution. ${ }^{3}$ Interestingly, in a necroscopic study where the bronchiolitis obliterans syndrome was the cause of death, airway scarring and collagen
Relatively little is known of the immunopathology of the airway following lung 
Table 1 Clinical details of stable transplant recipients

\begin{tabular}{|c|c|c|c|c|c|c|c|c|c|c|}
\hline $\begin{array}{l}\text { Patient } \\
\text { no. }\end{array}$ & Sex & Age & $\begin{array}{l}\text { Original } \\
\text { disease }\end{array}$ & $\begin{array}{l}\text { Days after } \\
\text { transplantation }\end{array}$ & $\begin{array}{l}\% \max \\
F E V_{1}\end{array}$ & $\begin{array}{l}\text { Rejection } \\
\text { grade* }\end{array}$ & $\begin{array}{l}\text { BAL } \\
\text { microbiology }\end{array}$ & $\begin{array}{l}\text { Cyclosporin level } \\
(\mu \mathrm{g} / \mathrm{l})\end{array}$ & $\begin{array}{l}\text { Dose of prednisolone } \\
(\mathrm{mg})\end{array}$ & $\begin{array}{l}\text { Dose of azathioprine } \\
(m g)\end{array}$ \\
\hline 1 & $M$ & 34 & B & 376 & 84 & $\mathrm{~A} 1 \mathrm{~B} 0$ & Nil & 162 & 15 & 25 \\
\hline 2 & $\mathrm{~F}$ & 32 & $\mathrm{CF}$ & 67 & 95 & A0B0 & Nil & 360 & 15 & 75 \\
\hline 3 & $\mathrm{~F}$ & 23 & $\mathrm{CF}$ & 102 & 100 & A0B 0 & Nil & 257 & 15 & 25 \\
\hline 4 & $\mathrm{~F}$ & 41 & $\mathrm{PPH}$ & 200 & 100 & $\mathrm{~A} 1 \mathrm{~B} 2$ & CMV,SA & 195 & 15 & 125 \\
\hline 5 & M & 36 & $\mathrm{CF}$ & 75 & 100 & $\mathrm{~A} 1 \mathrm{~B} 2$ & PsA,ASP & 820 & 20 & 75 \\
\hline 6 & $\mathrm{~F}$ & 34 & $\mathrm{E}$ & 190 & 100 & A0B0 & $\mathrm{CMV}$ & 264 & 15 & 75 \\
\hline 7 & $\mathrm{~F}$ & 35 & $\mathrm{E}$ & 419 & 100 & A0B 0 & Nil & 210 & 12.5 & 75 \\
\hline 8 & $\mathrm{~F}$ & 42 & $\mathrm{E}$ & 542 & 100 & $\mathrm{~A} 1 \mathrm{BX}$ & Nil & 134 & 7.5 & 50 \\
\hline 9 & $M$ & 22 & $\mathrm{CF}$ & 186 & 100 & $\mathrm{~A} 1 \mathrm{BX}$ & CMV & 432 & 7.5 & 50 \\
\hline 10 & $\mathrm{~F}$ & 31 & $\mathrm{CF}$ & 58 & 100 & $\mathrm{~A} 1 \mathrm{~B} 2$ & CMV & 710 & 20 & 50 \\
\hline 11 & $M$ & 33 & $\mathrm{E}$ & 1301 & 100 & A0B 0 & SPn & 265 & 7.5 & 100 \\
\hline 12 & $M$ & 46 & $S$ & 146 & 100 & A0B2 & CMV & 311 & 17.5 & 25 \\
\hline 13 & $\mathrm{~F}$ & 46 & B & 107 & 100 & A1BX & SA & 307 & 15 & 50 \\
\hline 14 & $\mathrm{~F}$ & 40 & B & 189 & 100 & A1B0 & Nil & 225 & 12.5 & 50 \\
\hline 15 & $M$ & 20 & $\mathrm{E}$ & 732 & 99 & A0B 0 & Nil & 243 & 7.5 & 100 \\
\hline 16 & $M$ & 39 & $\mathrm{CF}$ & 547 & 91 & A1B0 & PsA, CMV & 493 & 7.5 & 50 \\
\hline 17 & $\mathrm{~F}$ & 50 & $\mathrm{O}$ & 376 & 92 & $\mathrm{~A} 1 \mathrm{BX}$ & $\mathrm{CMV}$ & 402 & 15 & 75 \\
\hline 18 & $M$ & 55 & $\mathrm{O}$ & 545 & 99 & A1B3 & PsA,CMV & 301 & 7.5 & 100 \\
\hline \multicolumn{2}{|l|}{ Median } & 36 & & 195 & 100 & & & 283 & 15 & 63 \\
\hline \multicolumn{2}{|c|}{ Interquartile range } & $32-43$ & & $106-543$ & $98-100$ & & & $221-410$ & $7.5-15$ & $50-81$ \\
\hline
\end{tabular}

$\mathrm{B}=$ bronchiectasis $\mathrm{CF}=$ cystic fibrosis; $\mathrm{O}=$ emphysema; $\mathrm{S}=$ sarcoidosis; $\mathrm{E}=$ Eisenmenger's syndrome; $\mathrm{PPH}=$ primary pulmonary hypertension; $\mathrm{ASP}=$ aspergillus; $\mathrm{SPn}=$ Streptococcus pneumoniae; $\mathrm{SA}=$ Staphylococcus aureus; $\mathrm{PsA}=$ Pseudomonas aeruginosa (culture); CMV = cytomegalovirus (viral IF).

$* \mathrm{~A}=$ acute rejection $0-4, \mathrm{~B}=$ airway inflammation $0-4(\mathrm{X}=\text { ungradeable })^{1}$

deposition were more consistently found in large, rather than small, airways. ${ }^{11}$

Details of airway inflammation in asthma and chronic airflow limitation have evolved relatively recently, primarily using endobronchial biopsy (EBB) specimens to sample the bronchial mucosa directly. ${ }^{12}$ We have recently reported increased deposition of collagen in the airway of subjects with relatively mild asthma, ${ }^{14}$ suggesting that airway scarring in this situation may lead to fixed airway narrowing and rigidity. In subjects with chronic bronchitis Di Stefano and coworkers showed that there was a link between airflow limitation and the number of lymphocytes and macrophages in the bronchial mucosa. ${ }^{13}$ An inverse correlation was found between the number of $\mathrm{T}$ lymphocytes and the forced expiratory volume in one second $\left(\mathrm{FEV}_{1}\right)$. Data from lung transplant recipients are limited, ${ }^{8}$ but it is possible that similar mechanisms might explain fixed airway obstruction in asthma, chronic airflow limitation, and the lung transplantation bronchiolitis obliterans syndrome.

This study aimed to define inflammatory cells, activation markers, and $\mathrm{T}$ lymphocyte phenotypes present in EBB samples from a cross section of stable healthy lung transplant recipients compared with healthy controls. Characterising early immunopathological airway changes may prove relevant to understanding the later development of the bronchiolitis obliterans syndrome.

\section{Methods}

EBB specimens were taken from 18 stable lung transplant recipients (table 1 ) of median age 36 years (interquartile range 32-43). Eleven had received double lung transplants, five heart-lung transplants, and two single lung transplants. EBB samples were taken at the same time as routine surveillance of TBB samples and bronchoalveolar lavage (BAL) fluid (at two, four, eight, 12, 26, 39, 52 weeks and yearly thereafter). The interval from transplantation to the biopsy varied from 58 to
1301 days (median 195 days). All had $\mathrm{FEV}_{1}$ measurements at or near their maximal post transplant value (median $100 \%$, interquartile range $98-100 \%$ ) - that is, all were designated bronchiolitis obliterans syndrome (BOS) category $0 .{ }^{1}$ Patients were excluded if they had prior clinical likelihood of intercurrent lung infection or rejection. No patients were excluded after EBB samples were taken.

Nine asymptomatic non-smoking volunteers were recruited as controls. This group had a median age of 22 years (interquartile range 20-24). They were non-asthmatic and nonatopic, with a negative methacholine challenge. Controls were not age or sex matched as there is no current evidence that this affects EBB findings.

The study was approved by the Alfred Hospital ethics review committee.

Selection and procurement of the pulmonary donor was in accordance with guidelines described elsewhere. ${ }^{1516}$ No donor organs came from subjects with any form of airflow obstruction or known respiratory disease (according to donor hospital records).

All patients began triple immunosuppression therapy immediately after the operation. Maintenance therapy included cyclosporin (to achieve a blood level of 200-350 $\mu \mathrm{g} / \mathrm{l}$; EMIT assay, parent drug only (Syva, California, USA), azathioprine (1.0-2 mg/kg/day), and prednisolone $(0.15-0.25 \mathrm{mg} / \mathrm{kg} /$ day $) .{ }^{15}{ }^{16}$ Antilymphocyte preparations and inhaled steroids were not used in any patients.

Cyclosporin assay and lung function testing were undertaken immediately before the bronchoscopic examination. Spirometric tests were performed with a Masterscreen Spirometer (Jaeger, Wuerzburg, Germany) at two week intervals for up to six months after transplantation and monthly thereafter. The $\mathrm{FEV}_{1}$ was compared with the recipient's previous best value after transplantation to ascertain the percentage of maximal $\mathrm{FEV}_{1}$.

Fibreoptic bronchoscopy was performed under intravenous sedation with midazolam (Roche, France). The airways were an- 
Table 2 Cell surface markers in endobronchial biopsy samples from stable transplant recipients

\begin{tabular}{lcccccc}
\hline Patient no. & $C D 3$ & $C D 4$ & $C D 8$ & $C D 25$ & $H L A-D R$ & $C D 68$ \\
\hline 1 & 126 & 42 & 75 & 0 & 286 & 27 \\
2 & 21 & 12 & 16 & 1 & 63 & 79 \\
3 & 54 & 14 & 32 & 0 & 32 & 67 \\
4 & 106 & 44 & 49 & 0 & 129 & 172 \\
5 & 58 & 34 & 77 & 2 & 123 & 100 \\
6 & 141 & 104 & 122 & 0 & 105 & N/A \\
7 & 107 & 37 & 65 & 1 & 46 & 109 \\
8 & 282 & 122 & 216 & 12 & 364 & 432 \\
9 & 114 & 42 & 58 & 1 & 21 & 84 \\
10 & 40 & 18 & 28 & 0 & N/A & 71 \\
11 & 68 & 17 & 56 & 4 & 128 & 81 \\
12 & 92 & 50 & 56 & 1 & 116 & 92 \\
13 & 42 & 3 & 24 & 0 & 237 & 111 \\
14 & 80 & 34 & 92 & 0 & 172 & 200 \\
15 & 70 & 22 & 33 & 1 & 35 & 181 \\
16 & 31 & 14 & 37 & 3 & 21 & 166 \\
17 & 45 & 7 & 27 & 0 & 59 & 26 \\
18 & 35 & 6 & 30 & 1 & 0 & 54 \\
Median & 69 & 28 & 53 & 1 & 105 & 92 \\
Interquartile range & $42-109$ & $14-43$ & $30-76$ & $0-1.3$ & $34-151$ & $69-169$ \\
Control group & & & & & & \\
Median & 43 & 19 & 27 & 2 & 26 & 68 \\
Interquartile range & $34-83$ & $9-37$ & $16-44$ & $0-3$ & $12-64$ & $32-87$ \\
\hline
\end{tabular}

aesthetised with topical $1.5 \%$ lignocaine. Bronchoalveolar lavage of the middle lobe or lingula was followed by EBB, then TBB.

\section{ENDOBRONCHIAL BIOPSIES}

Four specimens were taken from lower lobe subcarinae with alligator forceps (Olympus, FB 15C, Japan) and placed into chilled saline. OCT embedded biopsies were snap frozen in a liquid nitrogen chilled isopentane slurry, then sectioned on a high performance cryostat.

Frozen tissue sections of $7 \mu \mathrm{m}$ were fixed in a paraformaldehyde based fixative (PLP) for 15 minutes at $4^{\circ} \mathrm{C}$ prior to staining. The staining panel (DAKO, Denmark) for lymphocyte typing included anti-CD3, CD4, and CD8. AntiCD25 and HLA-DR were used as cell activation markers and anti-CD68 was used as a marker of macrophages. Staining for cell subsets/activation markers was undertaken using a standard three layer immunoperoxidase stain (Vectastain Elite ABC kit, Vector Laboratories, California, USA).

For each monoclonal antibody or isotype control two sections $30 \mu \mathrm{m}$ apart were examined by a single observer, blind to the case. The submucosa was analysed to a depth of $150 \mu \mathrm{m}$ and counts were expressed per mm of basement membrane using a computerised colour image analysis system (Video Pro 32, Leading Edge, Sydney, Australia).

\section{TRANSBRONCHIAL BIOPSIES}

Between five and seven TBB samples were taken for staining with haematoxylin and eosin to assess acute rejection or histological obliterative bronchiolitis according to standard criteria. $^{2}$

ANALYSIS OF DATA

Minitab for Windows software (release 10.8) was used for statistical analyses. Cell counts in the EBB samples were compared using two tailed Mann-Whitney $U$ tests, $p$ values of $<0.05$ being considered significant. Correlation coefficients $(r)$ were obtained by Spearman's rank method.

\section{Results}

All patients were lung rejection grade A0 or A1. The bronchiolar component of the grading system demonstrated bronchioles present in 14 of 18 specimens (table 1). Bronchiolar inflammation was evident in four of these 14 samples.

Immunosuppression on the day the biopsy sample was taken is shown in table 1 . The median cyclosporin blood level was $283 \mu \mathrm{g} / 1$ (interquartile range 221-410), the median dose of prednisolone was $15 \mathrm{mg}$ daily (interquartile range $7.5-15 \mathrm{mg}$ ), and the median dose of azathioprine was $63 \mathrm{mg}$ daily (interquartile range $50-81 \mathrm{mg}$ ).

BAL culture or immunofluorescence demonstrated six bacteria and seven viruses in 11 recipients. All were considered both clinically and microbiologically to be commensals. Neither clinical nor histological pneumonitis and bronchitis were present and no patient had a history of infection or rejection in the previous two months. No cytopathic effect of cytomegalovirus was seen on cytological analysis of BAL fluid samples or histological analysis of TBB specimens.

There were no complications following EBB; specifically, there were no episodes of significant endobronchial haemorrhage or pneumothorax. The acquisition of EBB specimens added five minutes to the standard bronchoscopic procedure.

The analysis of cell surface markers in EBB samples from stable transplant recipients is shown in table 2 and fig 1 . There was a trend towards an overall increase in lymphocyte numbers, but with a significant increase only in the number of cells with CD8 positivity in the stable transplant population (median 53 (interquartile range 30-76) versus 27 (interquartile range $16-44$ ) cells $/ \mathrm{mm}$ basement membrane, $\mathrm{p}=0.04 ; 95 \% \mathrm{CI}$ for the difference 1 to 46). There was no difference in CD25 positive cells, but there was an increase in HLADR positive staining cells in the transplant recipients (median 105 (interquartile range 34151) versus 26 (interquartile range 12-64) cells $/ \mathrm{mm}$ basement membrane, $\mathrm{p}=0.03,95 \%$ CI for the difference 6 to 115). There was a trend towards an increase in CD68 positive cells (median 92 (interquartile range 69-169) versus 68 (interquartile range 32-87), $\mathrm{p}=0.07$, $95 \% \mathrm{CI}$ for the difference -1 to 84 ).

There was no correlation between individual EBB findings and the time after transplantation. The expected trend was seen for a lower dose of prednisolone with increasing time after transplantation $(r=0.71)$. Cyclosporin level and azathioprine dosage did not correlate significantly with time after transplantation. The blood levels of cyclosporin did not correlate with CD8 measurements. EBB findings did not correlate with age, sex, underlying condition, doses or blood levels of immunosuppressive agents. Importantly, the presence of bacterial or viral commensals in BAL fluid did not correlate with cell counts (table 3 ).

EBB findings did not correlate with the standard TBB bronchiolar grading of inflammation although, with only 14 evaluable 

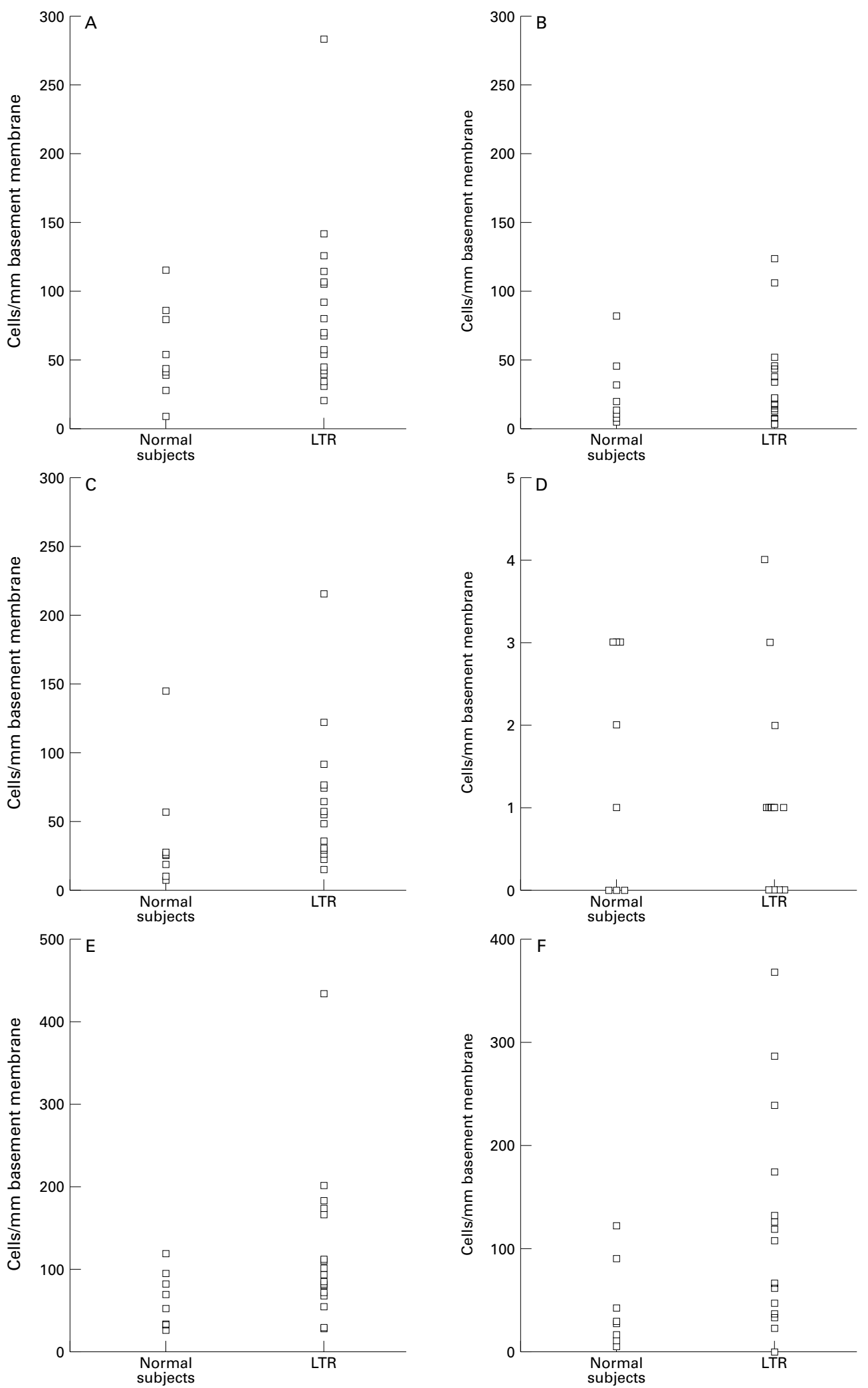

Figure 1 Cell counts per mm of basement membrane in endobronchial biopsy samples from lung transplant recipients and normal controls. (A) CD3 counts $(p=N S)$; (B) CD4 counts $(p=N S)$; (C) CD8 counts $(p=0.04)$; (D) CD25 counts $(p=N S)$; (E) CD68 counts ( $p=0.07) ;(F)$ HLA-DR counts $(p=0.03)$.

biopsy samples, numbers are small. All patients with bronchiolar inflammation on the TBB specimen remained BOS category 0 with a median follow up of 513 days (interquartile range 345-548) from when the EBB specimen was taken.

Only two patients developed the bronchiolitis obliterans syndrome during the follow up 
Table 3 Cell surface markers in endobronchial biopsy specimens from transplant recipients with and without organisms in bronchoalveolar lavage (BAL) fluid

\begin{tabular}{lcc}
\hline & $\begin{array}{l}\text { Recipients with } \\
\text { organisms in BAL fluid }\end{array}$ & $\begin{array}{l}\text { Recipients without } \\
\text { organisms in BAL fluid }\end{array}$ \\
\hline CD3 & $58(40-106)$ & $80(54-126)$ \\
CD4 & $18(7-44)$ & $34(14-42)$ \\
CD8 & $49(28-58)$ & $65(32-92)$ \\
CD25 & $1(0-2)$ & $1(0-1)$ \\
HLA-DR & $110(21-128)$ & $63(35-286)$ \\
CD68 & $88(67-125)$ & $109(67-200)$ \\
\hline
\end{tabular}

Values are medians (interquartile range)

\begin{tabular}{llll} 
Table 4 & Follow up details & \\
\hline Patient no. & $\begin{array}{l}\text { Days follow up } \\
\text { since biopsy }\end{array}$ & $\begin{array}{l}\text { Recent } \% \\
\text { max FEV }\end{array}$ & $\begin{array}{l}\text { Recent BOS } \\
\text { category }\end{array}$ \\
\hline 1 & 310 & 27 & 4 \\
2 & 876 & 100 & 0 \\
3 & 547 & 94 & 0 \\
4 & 539 & 86 & 0 \\
5 & 516 & 100 & 0 \\
6 & 517 & 99 & 0 \\
7 & 510 & 92 & 0 \\
8 & 98 & 99 & 0 \\
9 & 468 & 98 & 0 \\
10 & 552 & 89 & 0 \\
11 & 391 & 96 & 0 \\
12 & 542 & 100 & 0 \\
13 & 356 & 100 & 0 \\
14 & 391 & 90 & 0 \\
15 & 251 & 98 & 0 \\
16 & 265 & 95 & 0 \\
17 & 618 & 54 & 3 \\
18 & 645 & 96 & 0 \\
Median & 513 & 96 & 0 \\
Interquartile & $345-548$ & $92-99$ & $0-0$ \\
range & & &
\end{tabular}

range

$\mathrm{FEV}_{1}=$ forced expiratory volume in one second; $\mathrm{BOS}=$ bronchiolitis obliterans syndrome.

period (table 4). Patient 1 died of obliterative bronchiolitis and respiratory failure 319 days after the EBB specimen was taken, despite augmented immunosuppression. This condition was rapidly progressive, given the patient was still BOS category 0200 days after taking his biopsy specimen. Patient 17 progressed to BOS category 3 (starting 290 days after the EBB) and remains at this level a further 350 days later following augmented immunosuppression.

\section{Discussion}

This study confirms the practicability of performing and analysing EBB samples in lung transplant recipients. Specimens can be safely taken at the time of routine bronchoscopic follow up.

The published literature on lung transplantation provides little evidence for ongoing inflammation in the airways of healthy lung transplant recipients. Our study suggests that inflammation is present, although its aetiology is uncertain.

Our data contrast markedly with a recent study performed in a similar group by Fournier et $a l^{17}$ who reported significantly decreased mucosal $\mathrm{T}$ cell numbers and HLA-DR positivity. The immunosuppression doses used in this French study were not detailed for individual patients but cytolytic induction therapy was used. We could not discern a correlation between our spot levels of cyclosporin and EBB findings. However, the possibility that the observed CD8 signal in the EBB samples is due to our routine practice of decreasing the cyclosporin level with time after transplantation (and that the time since transplantation in our patient group was longer) may explain some of the apparent contradictions between the two studies. It is also notable that Fournier excluded patients with grade 1 acute rejection, a biopsy appearance that has hitherto been regarded as benign. This difference in biopsy profiles might explain the different results seen. An alternative and less conventional counting technique was used by Fournier, but this was not likely to explain the different results observed.

We chose to study stable non-rejecting transplant recipients in order to provide a suitable baseline of "normality" after pulmonary transplantation. On the other hand, the true stability of lung allografts is questionable. A steady increase in the incidence and severity of airflow obstruction as a function of time after lung transplantation has been described. ${ }^{18}$ As well as rejection, other factors such as infection, ischaemia, and denervation may influence the immunopathology of EBB samples after transplantation.

The absence of overt "lung" rejection as a cause of the changes noted was ascertained by the absence of clinical or laboratory evidence (from chest radiography, pulmonary function tests, BAL fluid and TBB samples) obtained at the time of bronchoscopy. It is known that clinical acute rejection will not be missed by these standard techniques. ${ }^{19}$ Even if a minor degree of lung rejection had been missed, in comparing airway immunoreactive $\mathrm{T}$ cells in rejecting and non-rejecting transplant populations Fournier ${ }^{17}$ concluded that acute rejection did not influence their number or activation status. Obliterative bronchiolitis, on the other hand, is notoriously difficult to detect in TBB samples..$^{5-7}$ No patient changed bronchiolitis obliterans syndrome category within six months of the study and this suggests that a clinically relevant bronchiolitis obliterans syndrome was not evident.

In our study population acute infection was an exclusion criterion, although several patients were colonised with bacteria or cytomegalovirus as evidenced from analysis of the BAL fluid. The presence of these organisms did not statistically relate to cell counts from the EBB samples in our study group (table 3). De Blic and coworkers noted similar findings in their study of parenchymal lymphocyte populations in TBB samples. ${ }^{20}$ Accumulated data from the literature on lung transplantation support this view. ${ }^{2122}$

The process of lung transplantation leaves proximal airways relatively ischaemic due to interruption to the bronchial blood supply. A lesion simulating chronic rejection has been described in rat renal isografts, ${ }^{23}$ a situation where alloreactivity is obviously absent, and the changes were presumably ischaemic in origin. Denervation and acute rejection around bronchial arteries can also affect vascular tone and permeability. ${ }^{24}$ Immunopathological changes could follow these events. However, in our study population measurements of cell markers did not relate to graft ischaemic times. 
The presence of covert airway inflammation in the setting of triple immunotherapy after transplantation parallels studies performed in asthmatic subjects. Corrigan ${ }^{25}$ has shown that not all asthmatic patients respond identically to treatment with glucocorticoids and cyclosporin in terms of inhibition of $\mathrm{T}$ lymphocyte function. Resistant patients have been shown to have significantly increased percentages of T cells expressing CD25 and HLA-DR surface markers of cell activation. The notion of a drug resistant population of cells in human lung allografts has been previously described. ${ }^{26}$ In addition, the transplantation of lungs from an asthmatic donor into a previously non-asthmatic recipient can precipitate apparent asthma despite triple immunosuppression. ${ }^{27}$

Generally, the presence of clinical obliterative bronchiolitis has been associated with a relative CD8 lymphocytosis in BAL fluid and TBB samples. ${ }^{28}$ Hruban and coworkers have demonstrated similar changes when comparing necropsy material from the airways of patients with the bronchiolitis obliterans syndrome and EBB samples from healthy transplant recipients. ${ }^{29}$ An early CD8 signal in EBB samples from healthy transplant recipients, as shown in our study, suggests the possibility of performing EBB (rather than TBB) to show early immunopathological changes that may be a marker of the bronchiolitis obliterans syndrome.

In lung tissue from transplant recipients lymphocyte expression of HLA-DR and CD25 in samples of BAL fluid and TBB material has been weakly correlated with the presence of either rejection or infection..$^{2030}$ However, immunosuppression with cyclosporin and prednisolone (in the asthma model) would both tend to decrease the expression of CD25 and HLA-DR. ${ }^{25}$ The absence of clinical infection in our study population suggests that subtle rejection mediated cellular activation may be present. HLA-DR has been linked with lymphocytes, macrophages, dendritic cells, fibroblasts, and endothelial cells, all of which have been implicated in allograft rejection and are present in the airway wall.

Increased macrophage numbers in our transplant population, as indicated by CD68 positivity, ${ }^{31}$ is also consistent with subtle allograft rejection. Paradis and coworkers have shown that macrophage numbers are increased in transplant recipients who reject the organ. ${ }^{32}$ Standard triple immunosuppressive therapy is relatively inefficient at inhibiting in vitro macrophage activity although the situation in vivo is not clear. ${ }^{31}$

The bronchiolar inflammation evident from TBB and EBB samples was not correlated with the development of the bronchiolitis obliterans syndrome in the two recipients who subsequently developed this complication.

In conclusion, studies utilising EBB samples from lung transplant recipients are safe and provide information regarding bronchial inflammatory changes. It appears likely that there is ongoing inflammation (possibly rejection mediated) even in healthy asymptomatic stable lung transplant recipients, despite standard triple immunosuppression. This is an important finding given recent work $^{13}$ showing that EBB evidence of inflammation in patients with chronic airflow limitation is inversely correlated with the $\mathrm{FEV}_{1}$. The potential roles of grade 1 acute rejection and bacterial or viral colonisation need to be clarified. Understanding the immune events that may precede the processes underlying airway scarring in transplant recipients may allow treatment to be directed to prevent the high mortality due to the bronchiolitis obliterans syndrome. However, longitudinal studies are now necessary to relate the relatively early and subtle changes in the airways we have described to the subsequent evolution of the bronchiolitis obliterans syndrome.

This study was supported by a grant from the Alfred Healthcare Foundation.

1 Cooper JD, Billingham M, Egan T, Hertz MI, Higgenbottom T, Lynch J, et al. A working formulation for the standardization of nomenclature and for clinical staging standardization of nomenclature and for clinical staging Transplant 1993;12:713-6.

2 Yousem SA, Berry GJ, Cagle PT, Chamberlain D, Husain AN, Hruban R, et al. Revision of the 1990 working formulation for the classification of pulmonary allograft rejection. F Heart Transplant 1996;15:1-15.

3 Yousem SA, Paradis IL, Dauber JA, Zeevi A, Rabinowich $\mathrm{H}$, Hardesty $\mathrm{R}$, et al. Large airway inflammation in heartlung transplant recipients: its significance and prognostic implications. Transplantation 1990;49:654-6.

4 Novick R J, Ahmad D, Menkis AH, Reid KR, Pflugfelder PW, McKenzie FN. The importance of acquired diffuse bronchomalacia in heart-lung transplant recipients with obliterative bronchiolitis. F Thorac Cardiovasc Surg 1991; 101:643-8.

5 Kramer MR, Stoehr C, Whang J, Berry J, Sibley R, Marshall $\mathrm{S}$, et al. The diagnosis of obliterative bronchiolitis after heart-lung and lung transplantation: low yield of transheart-lung and lung transplantation: low yield of trans-
bronchial biopsy. F Heart Lung Transplant 1993;12:675-81.

6 Yousem SA, Paradis I, Griffith BP. Can transbronchial biopsy aid in the diagnosis of bronchiolitis obliterans in biopsy aid in the diagnosis of bronchiolitis obliterans in
lung transplant recipients? Transplantation 1994;57:151-3

7 Chamberlain DJ, Maurer JR, Chaparro C, Idolor L. Evaluation of transbronchial lung biopsy specimens in the diagnosis of bronchiolitis obliterans after lung transplantation. F Heart Lung Transplant 1994;13:963-71.

8 Yousem SA, Ray L, Paradis IL, Dauber JA, Griffith BP. Potential role of dendritic cells in bronchiolitis obliterans in heart-lung transplantation. Ann Thorac Surg 1990;49 $424-8$

9 Azuma H, Tilney NL. Chronic graft rejection. Curr Opin Immunol 1994;6:770-6.

10 Al-Dossari GA, Jessurun J, Bolman M, Kshettry VR, King MB, Murray JJ, et al. Pathogenesis of obliterative bronchiolitis. Transplantation 1995;15:143-5.

11 Yousem SA, Suncan SR, Ohori NP, Sonmez-Alpan E. Architectural remodelling of lung allografts in acute and chitectural remodelling of lung allografts in acute and
chronic rejection. Arch Pathol Lab Med 1992;116:1175-80.

12 Holgate ST, Wilson JW, Howarth PH. New insights into airway inflammation and endobronchial biopsy. Am Rev airway inflammation and end

13 Di Stefano A, Turato G, Maestrelli P, Mapp C, Ruggieri $M$, Roggeri A, et al. Airflow limitation in chronic bronchitis is associated with T-lymphocyte and macrophage infiltration of the bronchial mucosa. Am f Respir Crit Care Med 1996;153:629-32.

14 Wilson JW, Li X, Kung I, Pain M. Lack of airway distensibility in asthma. Am Rev Respir Dis 1993;148:806-9.

15 Esmore DS, Brown R, Buckland M, Briganti EM, Rabinov $M$, Snell GI, et al. Techniques and results in bilatera sequential single lung transplantation. F Cardiac Surg 1994; 9:1-14

16 Cooper JD, Patterson GA, Trulock EP and the Washington University Lung Transplant Group. Results of single and bilateral lung transplantation in 131 consecutive recipients. F Thorac Cardiovasc Surg 1994;107:460-71.

17 Fournier M, Igual J, Groussard $\mathrm{O}$, Mal H, Sleiman C Duchatelle JP, et al. Mucosal T-lymphocytes in central Duchatelle JP, et al. Mucosal T-lymphocytes in central
airways of lung transplant recipients. Am $\mathcal{F}$ Respir Crit Care airways of lung transplant

18 Bando K, Paradis IL, Similo S, Konishi H, Komatsu K, Zullo TG, et al. Obliterative bronchiolitis after lung and heart-lung transplantation. F Thorac Cardiovasc Surg 1995 110:4-14

19 Pomerance A, Madden B, Burke MM, Yacoub MH. Transbronchial biopsy in heart and lung transplantation: clinicopathologic correlations. F Heart Lung Transplant 1995;14:761-3.

20 De Blic J, Peuchmaur M, Carnot F, Danel C, Deruesne M, Reynaud $\mathrm{P}$, et al. Rejection in lung transplantation - an 
immunohistochemical study of transbronchial biopsies. Transplantation 1992;54:639-43.

21 Nakehleh RE, Bolman RM, Hertz MI. Lung transplant pathology: a comparative study of acute rejection and CMV infection. Lab Invest 1991;64:A118.

22 Stewart S, Higgenbottam TW, Hutter JA, Penketh AR, Zebro TJ, Wallwork J. Histopathology of transbronchial biopsies in heart-lung transplantation. Transplant Proc 1988;20:764.

23 Tullius SG, Heemann U, Hancock WW, Azuma H, Tilney NL. Long-term kidney isografts develop functional and morphologic changes that mimic those of chronic allograft morphologic changes that mimic those

24 Higenbottam T, Jackson M, Rashdi T, Stewart S, Coutts C, Wallwork J. Lung rejection and bronchial hyper$\mathrm{C}$, Wallwork J. Lung rejection and bronchial hyper-
responsiveness to methacholine and distilled water in responsiveness to methacholine and distilled water in 140:52-7.

25 Corrigan CJ, Brown PH, Barnes NC, Tsai JJ, Frew AJ, Kay AB. Glucocorticoid resistance in chronic asthma. Am Rev Respir Dis 1991;144:1026-32.

26 Yousem SA, Sartori D, Sonmez-Alpan E. Multi-drug resistance in lung allograft recipients: possible correlation with the development of acute and chronic rejection. $f$ Heart Lung Transplant 1993;12:20-6.

27 Corris PA, Dark JH. Aetiology of asthma: lessons from lung transplantation. Lancet 1993;341:1369-71.

28 Whitehead BF, Stoehr C, Finkle C, Patterson G, Theodore $\mathrm{J}$, Clayberger C, et al. Analysis of bronchoalveolar lavage from human lung transplant recipients by flow cytometry. Respir Med 1995;89:27-34

29 Hruban RH, Beschorner W, Baumgartner W, Achuff S, Trail T, Marsh B, et al. Diagnosis of lung allograft rejection by bronchial intraepithelial Leu-7 positive T-lymphocytes. f Thorac Cardiovasc Surg 1988;96:939-46.

30 Clelland C, Higgenbottam T, Stewart S, Otulana B Wreghitt T, Gray J, et al. Bronchoalveolar lavage and transbronchial lung biopsy during acute rejection and infection in heart-lung transplant recipients. Am Rev Respir Dis 1993;147:1386-1392.

31 Schaberg T, Klein U, Rau M, Eller J, Lode H. Subpopulations of alveolar macrophes in smokers and nonsmokers. Am 7 Crit Care Med 1995;151:1551-8.

32 Paradis I, Zeevi A, Duquesnoy R, Hardesty R, Kormos R, Nalesnik M, et al. Immunologic aspects of chronic lung rejection in humans. Transplant Proc 1988;20:812-4. 